\title{
EDITORIAL
}

\section{La sociedad civil y la legislación para controlar el tabaquismo}

$\mathrm{L}$ os daños secundarios al tabaquismo tanto en el fumador activo como en el pasivo, han sido identificados desde hace muchos años. La comunidad médica internacional sabe que la causa evitable más importante de enfermedad y muerte es el tabaquismo, que contribuye en seis de las primeras ocho causas de muerte en el mundo. En México, las consecuencias secundarias al tabaquismo son un problema de salud pública mayor, como lo manifiesta la muerte de una persona cada nueve minutos. Dicho riesgo va en aumento. Dentro de 20 años, $80 \%$ de las muertes secundarias al tabaquismo se presentarán en países en vías de desarrollo, en contraste con el 25\% hace menos de 15 años.

Desde hace muchos años, diversos profesionales que laboramos en el sistema de salud mexicano, de manera individual y a través de diferentes instituciones, hemos externado nuestra preocupación sobre la magnitud del problema que causa el consumo de los diferentes productos elaborados con tabaco. Se han realizado múltiples simposios e impartido numerosas conferencias sobre los daños que el tabaquismo causa a la salud, a la economía y a la sociedad en general. A lo largo de estos años se ha destacado la importancia de proteger del humo de tabaco a las personas no fumadoras y en particular a los grupos de población más vulnerables, como niños, mujeres embarazadas y enfermos. Se ha conminado a directivos y funcionarios de diferentes instituciones a eliminar el humo de tabaco de los espacios públicos cerrados. En general, se ha tratado de informar y educar a la población sobre la necesidad de reducir el tabaquismo. Desafortunadamente, el impacto de este esfuerzo había sido mínimo. Y la razón es muy simple: el poder adictivo de la nicotina es enorme y su consumo en público no sólo ha sido legalmente permitido, sino considerado por muchos como una costumbre socialmente aceptada, inclusive elegante y atractiva. Ante esta situación, la única alternativa para regular el consumo del tabaco radicaba en la modificación de leyes que restringieran su consumo, enfocándose principalmente en la creación de espacios $100 \%$ libres de humo. Legislar a favor de la regulación en el consumo del tabaco no era una idea innovadora de la sociedad mexicana; en el ámbito mundial, durante los últimos 10 años los únicos países que han reducido el consumo del tabaco son aquellos protegidos con leyes que obligan al sector de la población que fuma, a no satisfacer su adicción a la nicotina de manera irrestricta y sin respeto a los demás. Aun así, la reducción en el número de fumadores en dichos países ha sido lenta: $9 \%$ en 10 años.

El proceso histórico mediante el cual el 26 de febrero de 2008 se aprobaran las leyes para el control del tabaco tanto en el ámbito local como en el federal, representa un excelente ejemplo de la cooperación y coordinación que puede y debe existir entre los cuerpos legislativos y la sociedad civil. Cuando menos, desde 2005 se desarrollaron foros de discusión en la H. Cámara de Diputados sobre tabaquismo y salud. Y el intercambio de información con los diputados de la Asamblea Legislativa del Distrito Federal se inició al año siguiente. Diversos legisladores, no únicamente los integrantes de las comisiones de salud, tuvieron el interés de trabajar en el tema y propiciaron un productivo acercamiento con quienes a través de la sociedad civil nos habíamos involucrado en el estudio del tabaquismo, sus consecuencias y las alternativas de solución. La sociedad civil estrechó sus lazos y se fortaleció no sólo con el apoyo de los diferentes elementos de carácter médico y científico, sino también con juristas, prestigiados encuestadores y otros grupos de profesionales que ayudaron a enfocar el problema de manera integral, ya que el tabaquismo, a diferencia de otras causas de enfermedad y muerte, es algo arraigado ancestralmente en las costumbres de muchas familias. El intenso intercambio con los legisladores permitió proporcionarles sólida información de carácter médico sobre las graves consecuencias del tabaquismo y los grandes beneficios derivados de su control. También se analizaron y aclararon los siguientes aspectos que aparentemente representaban argumentos 
válidos por parte de los fumadores:

1) Los espacios $100 \%$ libres de humo de tabaco son la única medida efectiva para proteger a los no fumadores de los riesgos de enfermedad y muerte prematura. Cuando menos $5 \%$ de los fallecimientos secundarios al tabaquismo se presentan en fumadores pasivos.

2) El derecho a fumar no existe, pero sí existe el derecho a la salud y es una obligación del Estado proteger a quienes pueden ser víctimas del humo de tabaco, que es el contaminante más peligroso que existe y responsable de más muertes que las secundarias en su conjunto al alcohol, drogas ilícitas y otros contaminantes. Defender el inexistente derecho a fumar sería como defender el derecho a contaminar.

3) Proteger a quienes no fuman del humo de tabaco también protege a las personas que fuman y de ninguna manera es una medida discriminatoria.

4) En los países que han implementado con éxito estas disposiciones, la mayoría de los fumadores han aceptado positivamente dichas leyes y han reducido su consumo de tabaco.

5) Parametría, empresa que colabora con el Consejo Mexicano Contra el Tabaquismo, realizó encuestas en noviembre de 2007 y principios de febrero de 2008 y encontró que más de $80 \%$ de la población aprueba las iniciativas que protegen a los no fumadores, y que $90 \%$ de los fumadores desean dejar de fumar y consideraron que estas medidas los ayudarían a alcanzar dicho objetivo. Cerca de $80 \%$ de los fumadores opinaron que si se prohibiera fumar en lugares cerrados asistirían con la misma o mayor frecuencia a restaurantes y otros locales comerciales.

6) La industria de la hospitalidad en países que ya gozan de estas medidas desde hace varios años no ha experimentado pérdidas económicas a mediano o largo plazo.

7) Reiteramos a los legisladores que la aprobación de estas leyes representaría un éxito para la sociedad mexicana y que no se arrepentirían a pesar de la incertidumbre e inquietudes lógicas que podrían experimentar al aprobar leyes tan trascendentes.

Es lógico que una minoría de fumadores se expresen de estas leyes como una medida autoritaria y absurda. Al contrario, este proceso legislativo establece un precedente de enorme valor sobre la forma de abordar un problema complejo de enorme trascendencia y que para su análisis requiere del trabajo en equipo de múltiples sectores de la sociedad. Las iniciativas legislativas son múltiples y de muy diversa índole, pero si éstas se analizaran con los respectivos expertos, el avance legislativo en México sería más rápido y efectivo.

Muchos se han preguntado, dadas las condiciones de nuestro país, cómo fue posible que se aprobaran estas leyes. La respuesta, que representa una gran lección para todos, es que en México se pueden hacer grandes cosas pero hay que trabajar para ello y no esperar mágicamente a que otros lo hagan.

Dr. Juan W Zinser

\footnotetext{
* Oncólogo. Instituto Nacional de Cancerología. Presidente del Consejo Mexicano Contra el Tabaquismo, México.
} 